\title{
Estados de contención, estados de detención. El control de la inmigración irregular en España. Ana López Sala y Dirk Godenau (coords.). Barcelona: Anthropos, 2017
}

\author{
Miguel Ángel Sánchez García \\ Universidad de Murcia \\ miguelangel.sanchez7@um.es
}

En la portada de Estados de contención, estados de detención aparece la silueta de una persona con capucha sobre una pared de color amarillo y ventanas azules. Deducimos que es una persona migrante, pero es imposible intuir su edad, nacionalidad 0 género. Podría ser la sombra de un individuo reflejada en la pared, pero aun así, esto no le confiere mayor corporeidad ni ofrece más información. Si miramos el fondo de la imagen, la pared amarilla, tampoco podemos adivinar en qué lugar se encuentra. Eso sí, no está en un espacio abierto, se halla dentro de algún lugar, estático, y sin que sea posible intuir un trayecto 0 un destino. Lo relevante de la portada no es, entonces, lo que muestra, sino lo que oculta, obligando al lector a mirar al migrante como habitualmente lo hace el control migratorio: despersonalizado y descontextualizado.

Si la portada simboliza el título, el propio título, a su vez, concentra el texto 0 , más apropiadamente, los textos. Los diez capítulos (incluida la introducción) que componen este trabajo recorren los diferentes espacios y mecanismos que configuran en la actualidad el control migratorio en España. Un recorrido que revela cómo los países receptores de inmigración irregular, entre ellos España, están apostando al control migratorio buena parte de sus esfuerzos económicos, policiales y legislativos reduciéndose a intrincados aparatos de contención y detención.

El libro forma parte del proyecto editorial Migraciones de Anthropos, que inició su andadura en 2001 con El impacto de la inmigración en la economía y en la sociedad receptora, coordinado por
Carlota Solé, y que cuenta con 29 títulos publicados hasta la fecha. Pertenecen a esta colección desde clásicos de los estudios migratorios como América inmigrante de Alejandro Portes y Rubén G. Rumbaut 0 La doble ausencia de Abdelmalek Sayad, hasta obras más recientes, donde se examinan las principales transformaciones de los regímenes de movilidad internacional y el control de los flujos migratorios. Este es el caso de Estados de contención, estados de detención, que cierra por el momento la colección.

Coordinado por Ana López-Sala (CSIC) y Dirk Godenau (Univ. de La Laguna), este trabajo tiene su origen en el proyecto MIND (Actores no estatales del control migratorio), del que Godenau y LópezSala forman parte, ésta última como investigadora principal. No obstante, ninguno de los dos son investigadores noveles en el estudio de las migraciones. Ambos cuentan con sólidas trayectorias en este campo, como reflejan distintas monografías, artículos y proyectos de investigación.

Prueba de ello es su labor de coordinación en este caso, que permite un diálogo fluido y sin solapamientos entre los autores y autoras de los textos. Voces que proceden de diversas disciplinas como la economía, la sociología, el derecho, la filosofía o la ciencia política, ofreciendo al lector una visión temática, teórica y metodológica muy completa sobre el tema, imprescindible para el especialista e interesante y accesible para el lector no experto.

El principal objetivo del libro es conocer cómo funciona el modelo español de control migratorio hoy, toda vez que se ha consolidado como uno de los ámbitos fundamentales de la política interior y 
exterior de España. Para ello, los autores proponen un enfoque versátil y multisituado, que entiende el control de inmigración irregular como un proceso dinámico que vincula a determinados actores (más allá del estado), espacios (más allá de las fronteras), tiempos (más allá de las entradas) y normativas (más allá de la Ley de Extranjería). Tomando como hilo conductor esta idea, a lo largo de los capítulos vamos a ir conociendo detalladamente nuevos agentes, prácticas, legislaciones, instrumentos y discursos que van completando el complejo puzzle en que se ha convertido la política migratoria española en las últimas dos décadas.

A todo lo anterior, no obstante, lo precede un texto introductorio que fija las claves del libro y funciona como marco general de lo que sigue. Uno de los principales aciertos de esta introducción es que sitúa la publicación de Estados de contención, estados de detención en el desplazamiento temático de los estudios migratorios en el campo académico español. Hasta mediados de los 2000 , las publicaciones se habían centrado en analizar la respuesta de la sociedad y las instituciones ante la llegada de población inmigrante. Pero la transformación del territorio español en uno de los principales receptores de flujos de migración irregular, las creativas y severas respuestas de los sucesivos gobiernos en términos de contención fronteriza y el incremento generalizado de la preocupación securitaria en 0ccidente, ha virado la atención de los especialistas hacia nuevos escenarios. Un cambio de foco del que da cuenta Estados de contención, estados de detención, recogiendo y ordenando algunas de las propuestas más recientes y destacadas.

Los capítulos se pueden organizar siguiendo los dos grandes objetivos que en la práctica tiene el modelo español de control migratorio: la contención, que se analiza en la primera parte, y la detención, que lo hace en la segunda. El primer capítulo, ¿Externalización del control migratorio o empoderamiento e instrumentalización de la inmigración? El caso de España-Marruecos, de Jonathan Zaragoza Cristiani, es un buen ejemplo de este cambio de enfoque. En él, el autor nos propone una revisión de los presupuestos más generalizados en la literatura académica sobre las estrategias de externalización llevadas a cabo por algunos países de la UE, entre ellos España. Una externalización que, en el caso de Europa, ha consistido en derivar la responsabilidad de la contención de inmigración irregular a los países magrebíes de origen y tránsito con el objetivo de impedir su entrada a Europa.

La hipótesis más aceptada en la actualidad explica que esta transferencia en la gestión de los flujos migratorios se sustenta en la desigualdad de poder y la supremacía de la UE respecto a los países del Magreb. Lo que plantea Zaragoza Cristiani, por el contrario, es que esta política hay que entenderla dentro de un marco de interdependencias entre países receptores y de tránsito/emisores, donde la externalización se daría más como resultado de negociación y cooperación bilateral que como imposición europea. Así, en el caso de España y Marruecos, el autor demuestra que el país norteafricano a través de estos acuerdos se ha beneficiado en términos de financiación, apoyo político interno y soberanía en el Sáhara Occidental, haciendo de ello la piedra angular de su política exterior. Mientras que España, ha conseguido reducir la inestabilidad de su frontera sur en momentos críticos e ignorar sus obligaciones en materia de derechos humanos, refugio y asilo.

En la línea del trabajo de Zaragoza Cristiani, otros autores examinan los costes que esta nueva obsesión fronteriza tiene para España, destacando su carácter paradójico. Por ejemplo, Domenech de la Lastra (2017), observa en la instalación de la triple valla que separa el territorio español del marroquí en Melilla, la prueba de cómo un estado es capaz de perder una parte de su territorio con tal de asegurar sus fronteras. Territorio que pasa a convertirse en "tierras de nadie" invisibles al derecho, "espacios de excepción fronteriza" (Domenech de la Lastra, 2017: 93) 0, siguiendo a Juan Carlos Velasco, "espacios de soberanía indiferenciada" (2015: 55).

Pero volvamos al libro. En otro capítulo, Fronteras sin derechos. Las "devoluciones en caliente", Margarita Fernández Escamilla investiga, precisamente, las razones que motivan a los estados a convertir las fronteras en "espacios sin derechos". El caso de las conocidas como devoluciones en caliente se relaciona directamente, según la autora, con esta nueva forma de entender las fronteras, 
donde lo importante reside en impedir que el migrante consiga llegar a territorio español y, por lo tanto, pueda hacer efectivos los derechos que lo amparan.

Según Fernández Escamilla, esta dinámica ha convertido a los espacios pre-fronterizos y fronterizos en una suerte de diques de contención que tienen como única misión evitar que los migrantes, percibidos como indeseables, entren en territorio de soberanía española. La lógica que subyace a estas nuevas medidas se hace cada vez más evidente con el tiempo: las fronteras ya no serían líneas administrativas que separan dos estados soberanos (borderline), sino zonas más amplias y más difusas (borderland) (Velasco, 2015: 57). Esta nueva concepción de la frontera, por ende, difumina el espacio físico de soberanía y, con ello, las responsabilidades de las instituciones españolas ante normativas de carácter internacional, comunitario y nacional que amparan a migrantes, refugiados y solicitantes de asilo.

La segunda parte del libro pone el foco en el control interno. Pasamos, por tanto, del Estado de contención al estado de detención. Entre los capítulos que integran esta sección, los lectores encontrarán planteamientos teóricos y hallazgos empíricos de notable interés para conocer el modo en el que se extiende el control migratorio una vez que el migrante ha superado la frontera. Trabajos que exploran, entre otros aspectos: a), cómo las actuaciones policiales en materia de extranjería tratan de forma discriminatoria a determinados grupos de población por su apariencia étnica; b), en qué medida los centros de internamientos para extranjeros (CIE) incumplen el ordenamiento jurídico a nivel nacional e internacional, y cuáles son sus funciones más allá de la privación de libertad; c), qué fases y actores participan en el sistema de deportación y cómo se implementa; y d), cuáles son los derechos que se vulneran en la puesta en práctica de las conocidas como expulsiones exprés, es decir, aquellas que se producen en menos de 72 horas tras la detención de un inmigrante en situación irregular.

Entre los capítulos que mejor describen los recientes cambios en el ámbito del control migratorio interno destaca La crimigración en el contexto es- pañol: el creciente protagonismo de lo punitivo en el control migratorio, firmado por José Ángel Brandariz y Cristina Fernández Bessa. En este trabajo, los autores rastrean la cada vez mayor conexión entre control migratorio y sistema penal en España. Con esa intención, analizan el aumento, a partir de 2010, de las catalogadas desde instituciones policiales como "expulsiones cualificadas", término con el que se diferencian las deportaciones vinculadas a la comisión de delitos 0 de inmigrantes con antecedentes penales, del resto de expulsiones. Según los datos del Ministerio del Interior, en 2016 el principal motivo de expulsión de ciudadanos extranjeros en España seguía siendo la estancia irregular. Sin embargo, esta categoría ha descendido desde 2008 más de un $42 \%$ sobre el total de deportaciones, al contrario que las expulsiones penales y la de extranjeros con antecedentes penales, que han crecido en el mismo periodo un 20,7\% y un $14,6 \%$, respectivamente. Esta evolución del sistema de deportación refleja, para Brandariz y Fernández Bessa, el giro punitivo y securitario que ha ido adoptando la normativa de control migratorio en España, en la que, a diferencia de otros países europeos, van adquiriendo mayor peso el internamiento y la expulsión por motivos penales.

Uno de los aspectos más relevantes de este texto es que sitúa la actual orientación del régimen de deportación español en las coordenadas de la nueva retórica sobre migración irregular en 0ccidente. Discursos oficiales que vinculan inmigración y delito, y que poco a poco se han ido incorporando a las legislaciones de distintos países, entre ellos España, desde que EE.UU. a finales de los años noventa aprobase la Illegal Inmigration Reform and Inmigrant Responsability Act.

Algunos autores han querido ver en este giro crimigratorio un síntoma de la respuesta que los estado-nación están ofreciendo a la ciudadanía en momentos de inseguridad social, crisis de legitimidad y pérdida de soberanía estatal. Antonio CampiIlo, por ejemplo, sostiene que en la actualidad asistimos a una "globalización amurallada" donde los inmigrantes sirven de coartada ante los efectos del capitalismo global: "Cuanto más crecen los riesgos generados por la ofensiva neoliberal, más crecen las reacciones xenófobas. [...] Se multiplican los 
muros fronterizos, los centros de internamiento, las expulsiones y repatriaciones de los «ilegales», los guetos urbanos, las urbanizaciones vigiladas, la seguridad privada, los ciudadanos de segunda y de tercera, el temor y el odio hacia los otros, y sobre todo hacia los parias que vienen de fuera" (Campillo, 2017: 41). Otros como Wendy Brown (2012), desde enfoques más alejados argumentan que la centralidad que ha alcanzado el control migratorio hoy se explica por la erosión que la globalización ha supuesto para la identidad y las fronteras de los estados-nación, especialmente en las democracias occidentales. La proliferación de muros, vallas y otros instrumentos de contención serían el atrezo de una escenificación teatral donde los estados recrean ante el público local la firmeza, el poder y el orden perdidos (Brown, 2012; Velasco, 2015). Sin embargo, el problema de este teatro es que sus representaciones superan por lo general la línea de la ficción y tienen un eco trágico en la realidad de una gran cantidad de seres humanos que aspiran a una vida mejor.

La tercera y última parte del libro retoma algunas de las dinámicas analizadas en los capítulos precedentes, pero abriendo nuevos senderos teóricos y empíricos. Es el caso de El Estado como instrumento irregularizador. Las políticas extraterritoriales de inmigración y emigración, de Sebastián Cobarrubias, que vuelve sobre la idea del Estado como productor de irregularidades. El autor propone pensar la irregularidad como un proceso gradual, heterogéneo y multidireccional, que no solo afectaría a la población inmigrante, sino que también puede extenderse a la población en general, cuestionando así la división migrante/ciudadano. Esta perspectiva, que vincula los derechos del inmigrante con el del resto de la ciudadanía nos recuerda, como ya expresó Saskia Sassen, que los derechos del migrante y el no migrante se vinculan tanto en el retroceso como en el progreso: "La historia demuestra que, en coyunturas críticas, reconocer las reclamaciones del inmigrante acaba ampliando los derechos formales de los ciudadanos" (Sassen, 2013: 13).

Del mismo modo, el capítulo elaborado por Ios coordinadores del libro, Delegando el control migratorio. Una aproximación a las dinámicas del outsourcing en España, aporta una mirada distinta, poco explorada hasta el momento, sobre las prácticas de outsourcing en el control de inmigración irregular. En su aproximación al problema, los autores proponen el concepto de "mercados del control migratorio", alrededor del cual realizan una caracterización de los actores no estatales que participan en el control migratorio a través de fórmulas como la delegación, financiación o subcontratación. Dentro de estos actores privados se encontrarían desde ONG que trabajan en labores de asistencia y atención con migrantes, hasta empresas de tecnologías de vigilancia y barrera dedicadas a la detección e interceptación de personas.

El lector podrá encontrar datos, argumentos e hipótesis que ayudan a iluminar los mecanismos legales y legislativos que han hecho posible la introducción del outsourcing en este ámbito, así como las razones de su aplicación y un recorrido por los principales escenarios donde estas dinámicas se han utilizado con mayor frecuencia. Sin embargo, Godenau y López-Sala plantean la necesidad de investigaciones empíricas que sigan indagando en esta dirección, debido a que aún existe un gran desconocimiento de las consecuencias que están generando este tipo de estrategias. Algo que obliga a mirar otros contextos, como por ejemplo EE.UU., donde la privatización y la externalización están consolidadas en instituciones públicas de seguridad.

$Y$ es que, de los variados estudios que han abordado este tema en EE.UU., se extrae una conclusión clara: el desarrollo de cárceles privadas ha dado como resultado un aumento de la población reclusa, convirtiendo al encarcelamiento masivo, según Saskia Sassen, en uno de los más poderosos "vehículos de expulsión en nuestra fase actual de capitalismo avanzado" (Sassen, 2015: 90). Teniendo en cuenta este precedente, ¿qué efectos puede tener la introducción de una lógica lucrativa en materia de control migratorio?, ¿cómo puede condicionar la intermediación de empresas privadas en la rendición de cuentas de la labor pública? y, lo más importante, ¿qué consecuencias tiene la participación de actores privados en la aplicación de normativas de carácter nacional e internacional, suscritas por España, que velan por los derechos de 
migrantes, refugiados y solicitantes de asilo? Estas y otras preguntas resaltan la necesidad de seguir cartografiando la realidad cambiante en que se ha convertido el control migratorio en España.

De hecho, este repaso que se propone aquí en forma de reseña resulta insuficiente para reflejar en su justa medida la abundancia de argumentos y hallazgos que contiene Estados de contención, estados de detención. A pesar de ello, quizá sí sirva para confirmar que estamos ante una obra imprescindible para investigadores e interesados en los estudios migratorios. En primer lugar, porque contribuye a un debate fundamental hoy, que interesa más allá de la academia; y lo hace en español y en formato libro, a pesar de los pocos incentivos que tienen los y las investigadoras en la actualidad para escribir monografías en español. En segundo lugar, porque sitúa el modelo español de control migratorio en un marco más amplio de transformaciones en el orden de la seguridad a nivel global y europeo. Y, en tercer lugar, porque propone una aproximación actualizada y multidisciplinar, accesible a un público amplio, que permite al lector disponer de una radiografía completa sobre el objeto de estudio.

Radiografía que muestra la deriva autoritaria que experimenta la Unión Europea, y en particular España, en materia de política migratoria. Pero también la resistencia, el activismo y la solidaridad que estas políticas están generando; una respuesta ciudadana que, como apuntan Natalia Moraes y Héctor Romero (2016), suele quedar invisibilizada entre la tormenta de xenofobia que asola Europa en nuestros días. Libros como Estados de contención, estados de detención desde el conocimiento científico contribuyen a promover una mirada crítica y rigurosa que nos avisa, de forma cada vez más clara, de una nueva destrucción del proyecto europeo.

\section{REFERENCIAS BIBLIOGRÁFICAS}

Brown, W. (2012). Desear muros, Relaciones internacionales, 19, 123-137.

Campillo, A. (2017). La Unión Europea ante los riesgos globales: hacia una estrategia de «seguridad humana». En Campillo, A. Guillén, C. y Cayuela, S. (eds.). Las (in)seguridades de Europa: una perspectiva crítica. Madrid, Marcial Pons, 21-56.

Domenech de la Lastra, P. (2017). Excepción en la frontera. Laberintos legitimadores de la violencia soberana en los límites del Estado. Ágora, 36, 2, 75-100.

Moraes, N. y Romero, H. (2016) (coords.). La crisis de los refugiados y los deberes de Europa. Madrid. Catarata.

Sassen, S. (2013). Inmigrantes y ciudadanos. De las migraciones masivas a la Europa fortaleza. Madrid, Siglo XXI.

Sassen, S. (2015). Expulsiones. Brutalidad y complejidad en la economía global. Madrid, Katz.

Velasco, J. C. (2015). El control de las fronteras y la justicia distributiva en un mundo globalizado. En Federico Arcos (ed.), La justicia y los derechos en un mundo globalizado, Madrid, Dykinson, 49-74. 